\title{
Impact of COVID-19 on Food Systems and Rural Livelihoods in Fogera Plain, Ethiopia
}

\author{
COVID-19 Country Report - September 2020 \\ Prepared by Abebaw Assaye and Dawit Alemu
}

\section{Introduction}

This report presents an early assessment of the impacts of the COVID-19 pandemic on agricultural commercialisation, food and nutrition security, labour and employment, and poverty and well-being in rural Ethiopia. Data was collected from a stratified random sample of 107 households (23 female- and 84 maleheaded). Respondents were drawn from a subset of households interviewed in a 2018 APRA survey of smallholder rice farmers in five kebeles (villages) in the Fogera Plain area of Amhara Region. The COVID-19 household survey data is complemented by data from 23 key informant interviews conducted in the kebeles. The data collection for this COVID-19 study will be carried out over three rounds. This report presents insights obtained from the first round conducted during late June/early July 2020.

\section{Context}

As a global threat, the impact of COVID-19 on food systems and livelihoods is associated with the economic and health challenges that emanate not only from domestic public policy measures, but also from actions taken by other countries, mainly in the form of trade restrictions. Following the confirmation of the first COVID-19 case in Ethiopia on 13 March 2020 and concerns about the sharp increase of cases, the federal government declared a state of emergency (SoE) on 10 April. This SoE resulted in the implementation of restrictions related to: (i) the movement of people and goods; (ii) control of food prices and other goods as per the SoE directives; and (iii) a reduction in public services, including those related to the operation of agri-food systems that are crucial for the livelihoods of rural communities.

\section{"We question whether COVID-19 is really a serious problem. We perceive it more as a political issue which is being used to impose controls on our behaviour. We have experience with many other health issues and diseases, such as malaria, which kills many more people each day than COVID-19." - Traditional leader, Kuhar Micheal Kebele, Fogera District}

\section{Health and disease}

All respondents - females and males - reported that they have heard and are aware of the COVID-19 virus, as well as the guidelines the government had put in place to control its spread. This was linked with awareness-creation activities at national, regional and local levels about the health risks of COVID-19. The main sources of information are health experts, kebele administration and development agents, and the media (radio, TV, and social media). However, many respondents reported that they did not believe the outbreak was that serious and were not following the guidelines strictly.

\section{Key findings}

- Overall, rice farmers in the study area were aware of COVID-19 threats and the prevention guidelines in place.

- Many respondents were sceptical about the seriousness of the outbreak; therefore compliance with government guidelines was limited.

- Agricultural activities have been minimally affected.

- Availability of agricultural inputs was reported to have declined by $31 \%$ of farmers; $71 \%$ stated they had encountered price increases.

- One-third (33\%) of respondents reported a reduction in their ability to sell produce in local markets, implying emerging challenges in marketing.

- These above trends are associated with a decrease in mobility and the reduced number of buyers and traders visiting local markets.

- There was also a perceived decrease in the food and nutritional security status of some respondents:

$\diamond \quad$ Since the start of COVID- $19,65 \%$ of female and $36 \%$ of male-headed households reported a reduction in their ability to eat healthy and nutritious food.

$\diamond \quad$ Both female and male farmers reported a modest decrease in the availability of various food items in local markets, ranging from $2 \%$ for meat to $20 \%$ for pulses.

\section{Farming, labour and marketing}

Results indicate that well over $90 \%$ of respondents have perceived no change in their ability to participate in normal farming activities. About $31 \%$ of respondents reported that

Proportion of repondents reporting decrease [negative impact of COVID-19]

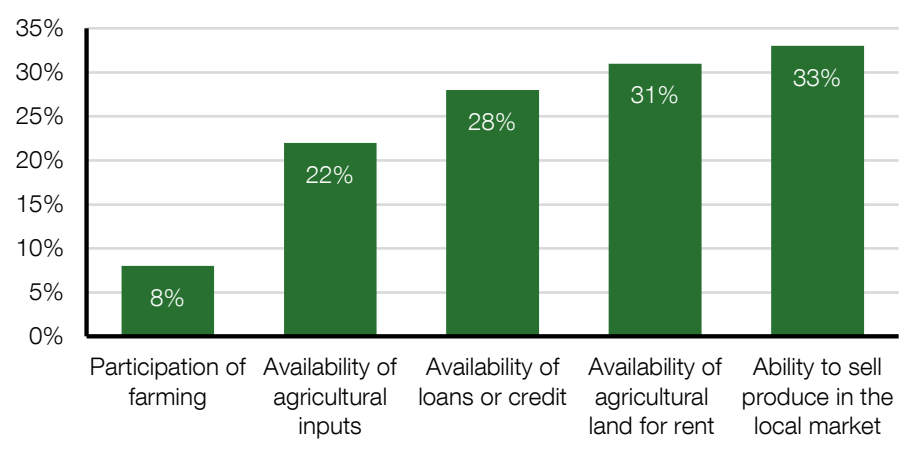


the availability of agricultural land for rent has decreased. About $22 \%$ of respondents reported that the availability of agricultural inputs related with seeds, fertilisers, agrochemicals, and veterinary drugs has decreased, while $71 \%$ reported an increase in the price of agricultural inputs. One-third (33\%) of respondents reported a decline in their ability to sell their produce in local markets. Some $28 \%$ of respondents reported a decline in the availability of loans or credit from banks or other financial institutions since the start of the crisis.

\section{Food and nutrition security}

- The response in relation to the availability of various food items since the start of the COVID-19 outbreak shows no statistically-significant difference between male- and female-headed households.

- The majority of respondents reported no change in the availability of different food items (grains, livestock products, pulses, root crops and vegetables), which are important to local diets.

- There was a statistically-significant difference between male- and female-headed households in relation to the different indicators of the perceived nutritional security due to the COVID-19 outbreak.

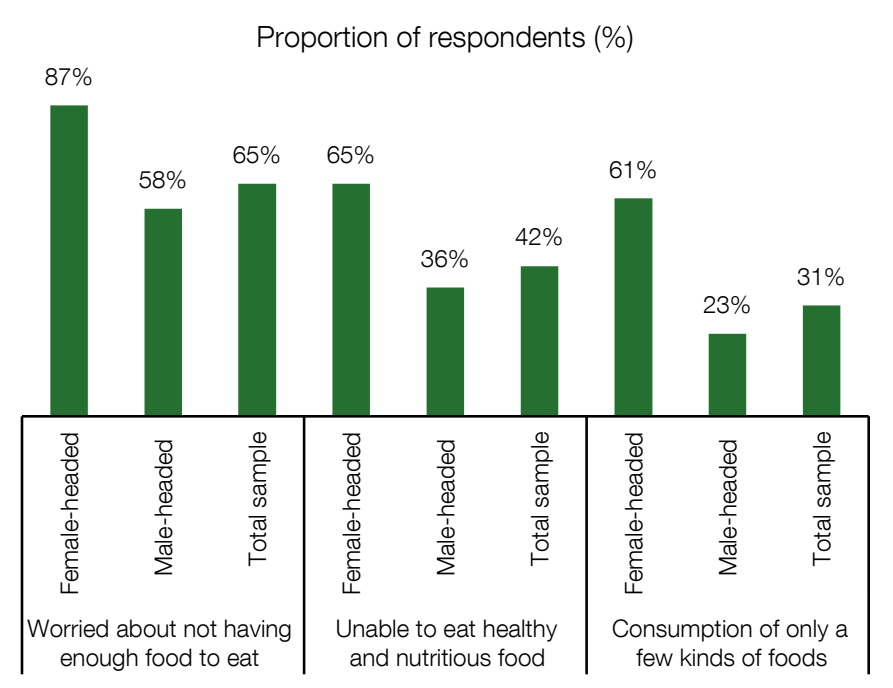

\section{Responses to the threat of COVID-19}

- Overall, there is no statistically-significant difference in the responses of female- and male-headed households to the perceived threats of COVID-19:

$\checkmark$ About $52 \%$ and $71 \%$ of respondents reported reduced movements within their villages and outside of villages, respectively.

$\checkmark$ Some $13 \%$ of all respondents reported a decrease in the number of buyers or traders coming to their village to do business.

$\diamond \quad$ In terms of changes in the roles of household members, $61 \%$ of respondents reported that girls have taken on more housework and care responsibilities, while $62 \%$ stated that boys have more farm work since the start of the crisis.
Proportion of respondents (\%)

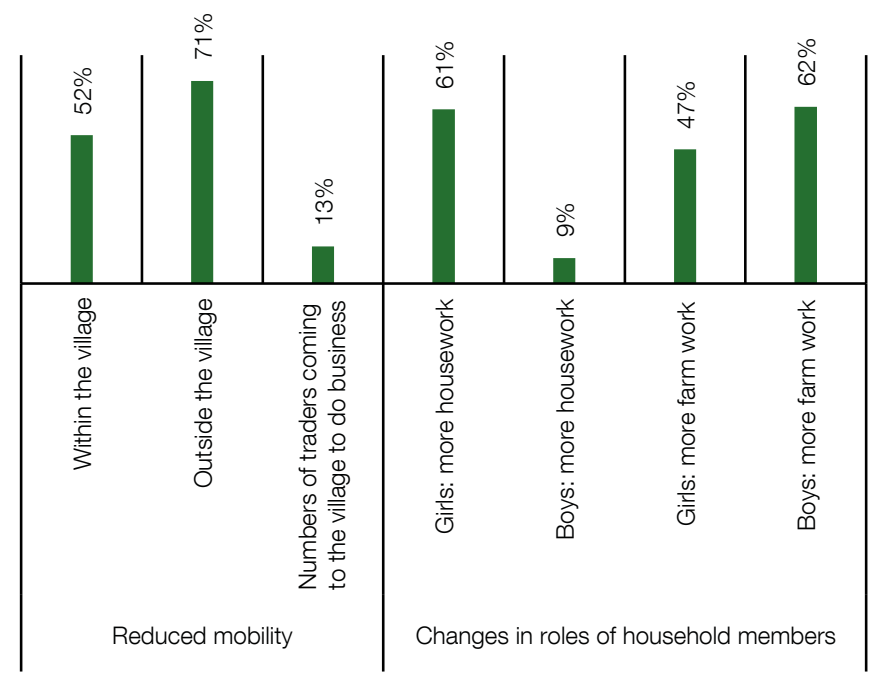

This is an Open Access report distributed under the terms of the Creative Commons Attribution Non Commercial No Derivatives 4.0 International licence (CC BY-NC-ND), which permits use and distribution in any medium, provided the original authors and source are credited, the work is not used for commercial purposes, and no modifications or adaptations are made.

If you use the work, we ask that you reference the APRA website (www.future-agricultures.org/apra/) and send a copy of the work or a link to its use online to the following address for our archive: APRA, Future Agricultures, University of Sussex, Brighton BN1 9RE, UK (apra@ids.ac.uk) 